\title{
Els llindars de les Alonsíades. Els paratexts en La Alonsíada, de Joan Ramis, i L'Alonsíada, de Vicenç Albertí
}

\author{
The thresholds of the Alonsiades. The paratexts in La Alonsíada, by \\ Joan Ramis, and L'Alonsíada, by Vicenç Albertí
}

\author{
Carlos Martínez Mayor \\ carlosmartinezmayor@hotmail.com
}

Universitat de València

\begin{abstract}
Resum: El 1818, lil lustrat menorquí Joan Ramis i Ramis (1746-1819) va publicar La Alonsíada, un poema èpic en castellà que narra la conquesta per part d'Alfons III d'Aragó de l'illa de Menorca l'any 1287, aleshores en mans sarraïnes. El mateix any es va imprimir també la traducció del text al català, L'Alonsíada, a cura del seu coetani Vicenç Albertí i Vidal (1786-1859). Tot i que es tracten d’una obra original i la seua traducció, hi ha diferències notables en la presentació de les dues versions. Aquestes divergències afectes aspectes de caire civil i polític, com són la finalitat de cada text o el públic al qual estaven adreçats. En aquesta línia, són molt interessants les implicacions que es desprenen dels paratexts presents en cadascuna de les composicions, ja que posen de manifest les distintes direccions preses per cada autor. Així doncs, en aquest article, partint de la tipologia paratextual proposada per Gérard Genette en Umbrales (1987), hem analitzat les diferències existents entre els paratexts de les dues obres. Aquest estudi ens ha permés concretar els punts civils i polítics en què divergeixen, els motius que van poder provocar les dissensions i la manera com es concreten en la globalitat de les dues obres.
\end{abstract}

Paraules clau: La Alonsíada, Joan Ramis, L'Alonsíada, Vicenç Albertí, paratext

\begin{abstract}
In 1818, the Menorcan enlightened Joan Ramis i Ramis (1746-1819) published La Alonsíada, an epic poem in Spanish that narrates the conquest by Alfons III of Aragon of the island of Menorca in 1287, then in Saracen hands. In the same year, the Catalan translation of the text, L'Alonsiada, was also printed by his contemporary Vicenç Albertí $i$ Vidal (1786-1859). Although they are an original work and its translation, there are notable differences in the presentation of the two versions. These divergences affect aspects of civil and political nature, such as the purpose of each text or the audience to which they were addressed. In this line, the implications that arise from the paratexts present in each of the compositions are very interesting, since they show the different directions taken by each author. Thus, in this article, based on the paratextual typology proposed by Gérard Genette in Paratext. Tresholds of interpretation (1987), we have analyzed the differences between the paratexts of the two works. This study has allowed us to specify the civil and political points in which they diverge, the reasons that could cause the dissensions and the manner in which they are specified in the globality of the two works.
\end{abstract}

Keywords: La Alonsiada, Joan Ramis, L'Alonsíada, Vicenç Albertí, paratext 


\section{Introducció}

El 1818, l'autor menorquí Joan Ramis i Ramis (Maó, 1746-1819) va publicar La Alonsíada. Es tracta d'un poema èpic, escrit en castellà, que narra la conquesta de Menorca l'any 1287, aleshores en mans sarraïnes, pel rei Alfons III d'Aragó. El mateix any de la mencionada publicació, Vicenç Albertí i Vidal (Maó, 1786-1859) va traduir el text de Ramis al català i el va publicar sota el nom de L'Alonsíada. Malgrat que la vida i la producció d'ambdós autors ha sigut tractada des de diverses perspectives, ${ }^{1}$ encara avui no comptem amb una edició crítica de cap de les dues composicions. Sí disposem, per contra, d'una edició facsímil duta a terme per Pons / Salord (1985) que recull ambdós textos: l'original en llengua castellana i la traducció catalana.

Els treballs de Ramis i Albertí són aleshores dues versions de la mateixa obra, on el canvi idiomàtic és un dels més evidents. No obstant això, no és ni de bon tros l'única diferència entre les dues composicions. En un altre treball ja hem explicat com Albertí va fer modificacions que afecten aspectes textuals tan diversos com el metre o el còmput total de versos (Martínez 2015: 72-84). Talment, també es va mencionar de manera succinta que les obres presentaven evidències que feien sospitar que un i altre text divergien en aspectes extraliteraris, de caire civil i polític, com són la finalitat que perseguia cada autor o el públic al qual s’adreçaven (Martínez 2015: 85-93). Són aquests punts en els quals ens centrarem en aquest article.

En aquest sentit, val a dir que la major part dels indicis que apunten en aquesta direcció es troben concentrats en els paratexts de les dues obres, és a dir, en els textos complementaris que acompanyen la composició poètica principal. Per aquest motiu, hem cregut convenient dur a terme una anàlisi de tots els paratexts presents en les dues obres.

Com que els estudis previs sobre les dues Alonsíades són escassos - i encara més pel que fa als seus paratexts-, a l'hora de comentar-los hem hagut de partir de la base. Per aquesta raó, hem fet servir les consideracions de Genette, autor del concepte paratext, que, en la seua obra Palimpsestos, els descrivia com el conjunt de:

\footnotetext{
título, subtítulo, intertítulos, prefacio, epílogo, advertencias, prólogo, etc.; notas al margen, al pie, finales; epígrafes, ilustraciones, fajas, sobrecubierta y muchos otros tipos de señales accesorias, autógrafas o alógrafas, que procuran un entorno (variable) y a veces un comentario oficial u oficioso del que el lector más purista y menos tendente a la erudición externa no puede siempre disponer tan fácilmente como lo desearía y lo pretende (1989: 11).
}

Posteriorment, Cayuela, a propòsit del Segle d'Or, ha sintetitzat la importància dels paratexts a l'hora de transmetre informació valuosa relativa als textos que acompanyen:

1 Vegeu, entre els més significatius, els estudis de Carbonell (1964a, 1964b, 1967 i 1968); Hernández (1987); Marfany (2016); Melchor (1982, 2001); Miralles (2007a, 2007b, 2012); Paredes (1999a, 1999b); Pons (1984, 1987, 1988); Salord, J. (1990, 2009 i 2012); i Salord, M. (1992, 1997). 
Les livres ont une mémoire. Ils conservent l'empreinte des imprimeries où ils sont nés, des lieux où ils ont été vendus, les lectures qu'on en a faites, des lectureurs qui les ont lus avant de traverser le temps pour arriver jusqu'à nous dans leur forme première et nous livrer, pour peu qu'on les interroge, les souvenirs de leur existence (1996: 7).

Per tant, durem a terme una revisió dels paratexts que apareixen en La Alonsíada de Ramis i L'Alonsíada d'Albertí, a fi de comparar-los entre sí i analitzar les implicacions polítiques, ideològiques i civils que se'n deriven. Per a això, hem partit de les reflexions i la terminologia sobre els paratexts fetes per Genette (2001 [1 ${ }^{\mathrm{a}}$ ed. 1997]). La manera de procedir ha sigut la mateixa en tots els casos: a partir de la definició de Genette de cada un dels paratexts, veure com es concreten en el cas de les obres que ens ocupen i analitzar els aspectes rellevants que es desprenen de cadascun d'ells.

A continuació mostrem en una taula comparativa els paratexts de La Alonsíada i L'Alonsíada:

Taula 1. Relació comparativa dels paratexts inclosos en La Alonsíada, de Joan Ramis, i L'Alonsíada, de Vicenç Albertí. Els espais en blanc indiquen que l'edició no compta amb una informació equivalent. Ombrejat, el text.

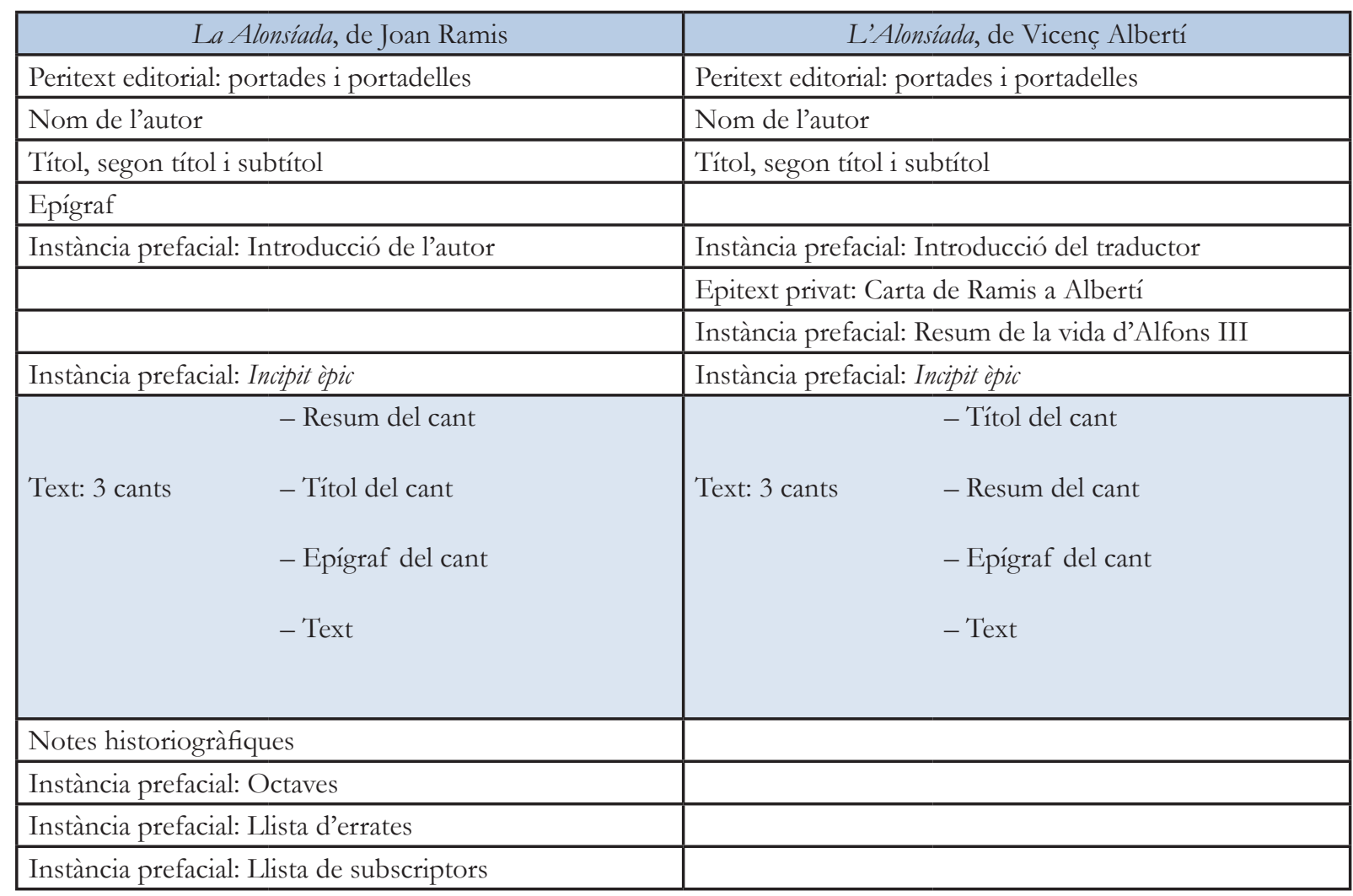




\section{El peritext editorial: les portades i les portadelles}

Tant La Alonsíada de Ramis com L'Alonsíada d'Albertí presenten un embolcall extern molt semblant. Genette bateja el conjunt de les portades i portadelles (a més d'altres elements més moderns com la sobrecoberta o la faixa) com peritext editorial, definit com, «toda esa zona del peritexto que se encuentra bajo la responsabilidad directa y principal (pero no exclusiva) del editor (...). El rasgo característico de este aspecto del paratexto es esencialmente espacial o material; se trata del peritexto más exterion» (2001: 19).

Així, és important assenyalar que la responsabilitat de les mesures preses en els peritexts de les obres que ens ocupen no la podem atribuir a Ramis o Albertí, -O almenys no en el mateix grau que les decisions preses en el propi text o en la resta de paratexts-, ja que desconeixem fins a quin punt van ser decisions preses pels autors o per l'editor.

En les dues Alonsíades, les portades compten amb diferent informació, com es veu a la següent taula:

Taula 2. Comparació dels elements de les portadelles de les dues edicions. Els espais en blanc indiquen que l'edició no compta amb una informació equivalent.

\begin{tabular}{|c|c|c|}
\hline & & \\
\hline & La Alonsiada, de Joan Ramis & L'Alonsiada, de Vicenç Albertí \\
\hline Títol & La Alonsíada & L'Alonsíada \\
\hline Segon títol & $\begin{array}{l}\text { o Conquista de Menorca por el rey } \\
\text { don Alonso III de Aragón en } 1287 .\end{array}$ & $\begin{array}{l}\text { o Conquista de Menorca pel rei } \\
\text { don Alonso III d'Aragó en } 1287 .\end{array}$ \\
\hline Subtítol & $\begin{array}{l}\text { Poema en III cantos e ilustrado con } \\
\text { notas }\end{array}$ & $\begin{array}{l}\text { Poema en tres cants. Escrit en } \\
\text { castellà }\end{array}$ \\
\hline Autor & $\begin{array}{l}\text { por el doctor don Juan Ramis } \\
\text { y Ramis, individuo de la Real } \\
\text { Academia de la Historia, etcétera. }\end{array}$ & $\begin{array}{l}\text { pel doctor don Juan Ramis i Ramis, } \\
\text { indivíduo de la Real Acadèmia de la } \\
\text { Història, etcètera. }\end{array}$ \\
\hline Traductor & & $\begin{array}{l}\text { Traduilt per don Vicent Albertí i } \\
\text { Vidal. }\end{array}$ \\
\hline Filigrana & & $\begin{array}{l}\text { Un motiu vegetal amb simetria } \\
\text { radial, justificat al centre de la } \\
\text { pàgina. }\end{array}$ \\
\hline Informació editorial & Con licencia. & Ab llecència. \\
\hline Nom i direcció de l'editor & $\begin{array}{l}\text { Mahón, en la imprenta de } \\
\text { Pedro Antonio Serra, calle de la } \\
\text { Arravaleta, número } 37 .\end{array}$ & $\begin{array}{l}\text { Maó, en la imprenta de Pere Antoni } \\
\text { Serra. }\end{array}$ \\
\hline Any de publicació & Año de 1818. & 1818 \\
\hline
\end{tabular}


La informació relativa al títol, el segon títol, el subtítol i l'autor és idèntica en les dues edicions. Tanmateix, com que es tracta d'elements amb una entitat significativa, detallarem les seues implicacions posteriorment, en dos epígrafs independents.

A continuació trobem un parell d'informacions que únicament es troben en L'Alonsíada catalana. Són l'explicitació del nom del traductor i l'aparició d'una filigrana, un motiu vegetal imprés que no té altra finalitat que l'estètica.

Finalment, trobem la informació editorial, el temps i el lloc on van ser impreses les obres. Ambdues portades coincideixen en aquests punts i ens indiquen que els treballs van ser impresos el mateix any en la impremta de Pere Antoni Serra. En aquest sentit, l'única diferència present és que en Ramis es concreta la direcció del taller: el número 37 del carrer de s'Arravaleta, a Maó, un carrer que encara avui conserva la mateixa denominació.

\section{E1 nom de l'autor}

El nom de l'autor, Joan Ramis, es troba indistintament en les dues versions del text. Pel que fa a la seua aparició, i d'acord amb la tipologia de Genette (2001: 36-50), es tracta d'una autoria circumscrita a la portadella i ònima (ja que s'explicita el nom de l'escriptor, en oposició a les modalitats de l'anonimat i el pseudonimat). Segons el teòric francés, la menció de l'autoria

cumple una función contractual de importancia variable según el género; débil o nula en ficción, mucho más fuerte en todas las clases de escritos referenciales, en los que la credibilidad del testimonio o de su transmisión se apoya en la identidad del testigo o del relator (2001: 39).

En altres paraules, la menció del nom de l'escriptor dóna credibilitat als fets descrits en el text. Consegüentment, destaca també el tractament de doctor donat al literat, que es va doctorar en dret canònic i civil (Más / Perelló 2003-2006: 128), i la menció del càrrec de Ramis com a membre de la Real Academia de la Historia. Segons Gella (1989: 25), aquesta signatura, o una similar, apareix de pròpia mà en les obres de Ramis a partir de 1789, dos anys després del seu nomenament com a membre de l'Academia.

En el cas de les Alonsíades, és significativa l'aparició del càrrec d'acadèmic de Ramis perquè l'obra conjumina la forma d'un poema èpic amb el contingut d'un tractat historiogràfic. En qualsevol cas, la menció de l'autor, del seu tractament de doctor i del seu càrrec han d'interpretar-se com a segell valedor que els successos relatats són producte d'una intensa recerca científica i que, per tant, han de ser interpretats com verídics; això sí, amb excepcions evidents, com l'aparició del monstre mitològic de l'Enveja en el cant I o tot el cant II. 
Carlos Martínez Mayor. Els llindars de les Alonsíades. Els paratexts en La Alonsíada, de Joan Ramis, i L'Alonsíada, de Vicenç Albertí

\section{El títol, el segon títol i el subtítol}

Com hem dit abans, les dues composicions tenen un títol, segon títol i subtítol semblants. Tots tres estan circumscrits a l’àmbit de la portadella i són originals de la primera i única edició. Igualment, sembla que eren controlats per Ramis en la versió original i que Albertí no va fer cap canvi en la traducció al català.

Genette (2001: 70) distingeix dues categories titulars: la temàtica (els títols que fan referència al tema de l'obra) i la remàtica (aquells que en descriuen l'estructura o la forma). Malgrat això, el propi narratòleg adverteix que no es tracta de compartiments estancs, sinó que els dos àmbits poden conviure en un mateix títol. Així, exposa el cas de les epopeies clàssiques a la manera de l'Eneida, en què es combina el nom de l'heroi (i, per tant, temàtic), amb els sufixos -ida, -ada, característics d'aquests tipus d'obres (i, per tant, remàtic). És en aquesta filiació en la qual hem de considerar les dues Alonsíades.

Igualment, hem de tenir en compte el que Genette anomena connotacions del títol, «efectos semánticos, efectos secundarios (...) que se refieren a la manera en que el título, temàtico o remàtico, ejerce su función» (2001: 79). Certament, la decisió d'anomenar el text a la manera de les grans epopeies clàssiques no pot interpretar-se sinó com una decisió conscient d'integrar l'obra dins d'aquesta tradició, cosa que, al mateix temps, la revesteix amb una pàtina de dignitat històrica i grandiositat.

El segon títol (Conquista de Menorca por el rey don Alonso III de Aragón en 1287 / Conquista de Menorca pel rei don Alonso III d'A ragó en 1287) ve introduit per la conjunció disjuntiva o, i, per tant, ha d'interpretarse com a equivalent al títol. A diferència d'ell, el segon títol és clarament de tipus temàtic, ja que evidència la matèria que tracta el poema i ens situa en un pla històric.

Pel que fa al subtítol, hem d'interpretar-lo com una indicació genèrica, «un anexo al título, más o menos facultativo (...) y por definición remàtico, en tanto destinado a hacer conocer el estatus genérico intencional de la obra» (Genette 2001: 83). Així, els subtítols de les dues versions indiquen que es tracta d'obres poètiques organitzades en tres cants, un tret comú en els grans poemes narratius. Igualment, aquesta distinció pot ser intencional, per tal de remarcar el canvi de direcció respecte al gruix de la producció de cadascun dels seus responsables (la historiografia en el cas de Ramis i el teatre, en el d'Albertí).

De la mateixa manera, destaca que la portadella del primer, en castellà, menciona que es tracta d'un poema «ilustrado con notas», mentre que en el cas del segon no trobem cap referència similar. Aquesta al lusió remet a un conjunt de notes historiogràfiques que Ramis va adjuntar a La Alonsíada castellana i que Albertí va obviar en la traducció al català. Les implicacions despreses de la inserció o supressió d'aquestes notes seran analitzades més avant. També cal remarcar que la portada de la versió d'Albertí evidencia que la seua és una traducció, ja que l'original va ser «escrit en castellà». 


\section{Els epígrafs}

El següent paratext que comentarem és l'epígraf, entés per Genette com «una cita ubicada en exergo, generalmente al frente de la obra o de parte de la obra» (2001: 123). Segons ell, la pràctica d'epigrafiar les publicacions va sorgir a França al segle XVII, i es va estendre al llarg del segle XVIII, amb la costum d'epigrafiar les grans obres amb cites en llatí dels autors clàssics.

D'acord amb aquesta tendència, tots els epígrafs, tant de La Alonsíada com de L'Alonsíada, procedeixen de l'Eneida de Virgili i conserven el llatí original. Així, els tres actors implicats en la transmissió dels epígrafs són l'epigrafiat o autor original, és a dir, Virgili, en aquest cas; l'epigrafista, que còpia a l'epigrafiat, Ramis, que va introduir les sentències en La Alonsíada; i el destinatari de l'epígraf, que és el lector virtual de l'obra, ja que els epígrafs en tot moment formen part del primer grau de la narració i, per tant, són extradiegètics.

Malgrat això, les dues Alonsíades divergeixen en el còmput total d'epígrafs. Així, l'edició castellana en compta amb quatre, un inicial al començament de l'obra i tres més, que obrin cadascun dels cants en què està dividit el poema. En la traducció catalana, en canvi, l'epígraf inicial va ser suprimit i solament compta amb els tres epígrafs dels cants. Ignorem els motius pels quals Albertí o l'editor van suprimir l'epígraf inicial però va mantenir la resta.

L'epígraf inicial de La Alonsíada, «Non illi quisquam se impune tulisset / obvius armato; seu cum pedes iret in hostem, / seu spumantis equi foderet calcaribus armoss, ${ }^{2}$ pertany al llibre VI, versos 879-881 de l'Eneida. Originàriament, són les paraules d'Anquises al seu fill Enees, després de trobar-se amb Marc Claudi Marcel. Cal remarcar que Ramis, quan copia la sentència, elimina el subjecte. Per tant, el receptor de les qualitats bèl liques descrites ha d'interpretar-se respecte a la resta de paratexts i del text de $L a$ Alonsíada, i acaben recaient sobre l'heroi les gestes del qual es glossen: Alfons III d'Aragó.

Aquesta pràctica d'obviar el subjecte original per relocalitzar les virtuts descrites sobre la figura del monarca aragonés reapareix en els epígrafs posteriors. Aquests epígrafs són, per al primer, «Bella, horrida bella», ${ }^{3}$ (VI, v. 86); per al segon, «Sunt lachrimae rerum, et mentem mortalia tangunt», ${ }^{4}$ (I, v. 462); i, per al tercer, «Pariter pietate / vel armis egregium ${ }^{5}$ (VI, vv. 769-770).

Pel que fa a les funcions dels epígrafs, aquests serveixen per comentar el títol, comentar el text, indicar l'època i/o gènere del text, i servir de garantia a través de l'epigrafiat. La primera funció ve donada per l'epígraf inicial, que reforça la idea d'epopeia clàssica introduïda pel sufix -íada del

\footnotetext{
3 《Guerres, esgarrifoses guerres», (Dolç 1975: II, 133).

4 《Hi ha llàgrimes per a l'infortuni, i les coses humanes toquen el cor», (Dolç 1975: I, 137).

5 《El qual excel lirà igualment per se la seua pietat i les seues armes», (Dolç 1975: II, 168).
}

2 Segons la traducció de Dolç (1975: II, 175-176): 《Ningú no s'hauria aixecat impunement contra aquest jove armat, tant si ell hagués marxat a peu cap a l'enemic com si hagués agullonat amb els esperons els costats d'un cavall escumós». 
títol i delimita la composició com un himne a l'heroi objecte de la lloança. La cita col loca el poble menorquí a la mateixa altura que altres pobles de la tradició clàssica, al conferir-li uns orígens quasi mítics. De la mateixa manera, glossa la figura del monarca, autor de les gestes descrites, i incita el públic a lloar-lo, especialment el dia 17 de gener, aniversari de la conquesta. Aquesta idea apareix repetida després en els versos 9-12 del poema, que formen part de l'incipit èpic i en què s'argumenta en favor de commemorar la data amb un celebració.

Com dèiem abans, desconeixem els motius pels quals Albertí va obviar aquest epígraf en la traducció catalana, tot i que el fragment no és decisiu per comprendre el text. Entre les possibles hipòtesis, especulem amb que, bé el menorquí considerava que el títol ja era indicatiu suficient del contingut de l'obra; bé pensava que el fragment inicial trencava l'estructura de l'obra i preferia deixar únicament un epígraf per cant; o bé simplement es va tractar d'un oblit. Talment, no podem descartar que es tracte d'un error imputable a l'impressor, fet versemblant si tenim en compte que els altres epígrafs sí es van mantenir.

La segona funció, la del comentari del text, ve donada pels epígrafs que introdueixen cada cant. Aquests fragments marquen el tema principal de cadascuna de les parts de la composició. En conseqüència, el vers «Bella, horrida bella» remet els successos bèl lics narrats en el primer cant, sobre la conquesta de Menorca per Alfons III. El vers «Sunt lachrimae rerum, et mentem mortalia tangunt» denota el canvi de direcció en el segon cant, que passa de l'èpica a la tragèdia per relatar la desgràcia d'Osman i Zaida, dos enamorats àrabs, després de la derrota de l'exèrcit. Finalment, els versos «Pariter pietate / vel armis egregium» fan referència a l'excel lència del monarca, tant en la guerra com en la pau, ja que el tercer cant glossa les mesures preses pel rei per reestructurar l'illa.

La tercera funció té a veure amb el caràcter significatiu que els epígrafs tenen segons determinats gèneres i/o períodes històrics. I és que la pràctica d'epigrafiar ha sigut desigual segons els moviments estètics i els gèneres literaris conreats. Ara no comentarem quins van ser els períodes, moviments i gèneres més prolixos en la pràctica, però sí volem remarcar la importància del fet que Ramis elegira Virigili i l'Eneida per il lustrar La Alonsíada, ja que les dues composicions comparteixen trets comuns significatius.

D'aquesta manera, el text del poeta clàssic narra les vicissituds d'Enees, que conclouen en l'assentament del troians a Itàlia i la fundació de Lavínium, mentre que el del menorquí recorre una línia semblant, tot substituint l'heroi i la ciutat italiana per Alfons III d'Aragó i l'illa de Menorca. Per tant, a banda del propi text en sí mateix, és a través dels epígrafs que l’obra de Ramis enllaça amb les grans epopeies de l'antiguitat clàssica i connecta amb el gènere de l'èpica. Talment, s'incideix un vegada més en els orígens èpics de Menorca i la seua població. Aquesta pràctica, de fet, va ser habitual en les literatures europees del segle XVIII. Així, Ayensa argumenta que aleshores estava estesa

la creença més o menys generalitzada que una epopeia immortalitzava un autor i una literatura, la qual cosa explicava que aquelles literatures que no disposaven de cap epopeia antiga, medieval o renaixentista, maldessin per aconseguir-la (2008: 118). 
Finalment, la darrera funció dels epígrafs és l'efecte garant que produeix el fet de citar un autor o altre. Talment, la citació d'una obra i un autor clàssic s'ha d'interpretar com un moviment de Ramis per conferir una aura de dignitat i rellevància a la seua propia obra, però també a sí mateix. Tal com apunta Genette:

El epígrafe es un signo de cultura, de intelectualidad. Esperando las hipotéticas reseñas de las gacetas, premios literarios y otros reconocimientos oficiales, el epígrafe es casi la consagración de un escritor, que por él elige sus pares y su lugar en el Panteón (2001: 136).

\section{Les instàncies prefacials}

Segons Genette (2001: 137), la instància prefacial és tot aquell text «liminar, autoral o alógrafo, que constituye un discurso producido a propósito del texto que sigue o que precede». Si precedeix el text, aleshores rep el nom de prefaci; si hi va a continuació, s'anomena postfaci.

En el cas que ens ocupa, també trobem diferències significatives entre les instàncies prefacials que Ramis i Albertí van afegir als seus texts. Per tal de clarificar les divergències, hem elaborat la següent taula. Tot seguit, passarem a comentar-les de manera individual:

Taula 3. Comparació de les instàncies prefacials de les dues edicions. Els espais en blanc indiquen que l'edició no compta amb una instància prefacial equivalent.

\begin{tabular}{|l|l|l|}
\cline { 2 - 3 } \multicolumn{1}{c|}{} & \multicolumn{1}{|c|}{ La Alonsíada, de Joan Ramis } & \multicolumn{1}{c|}{ L'Alonsíada, de Vicenç Albertí } \\
\cline { 2 - 3 } & Introducció de l'autor & Introducció del traductor \\
\cline { 2 - 3 } & Incipit èpic & $\begin{array}{l}\text { Resum de la vida d'Alfons III } \\
\text { d'Aragó }\end{array}$ \\
\cline { 2 - 3 } Postfacis & Octaves & Incipit èpic \\
\hline & Llista d'errates & \\
\cline { 2 - 3 } & Llista de subscriptors & \\
\hline
\end{tabular}

\subsection{Les introduccions}

La primera instància prefacial que trobem en les dues edicions és una introducció. En ambdós casos es tracta de texts en prosa, contemporanis de l'edició original. Tanmateix, les instàncies divergeixen pel que fa al destinatari. Així, segons la classificació proposada per Genette (2001: 154), la instància de La Alonsíada és de tipus autoral, autèntic i assertiu — pertany a una persona real, l'autor del text, que no rebutja l'obra com a pròpia-, mentre que la instància de L'Alonsíada és al lògrafa i autèntica, ja que pertany a una persona real, però no a l'autor del text, sinó al traductor. El 
destinatari dels dos prefacis és el lector del text, ja que no n'apareix mencionat cap altre (imaginari o no) que funcione com a mediador.

En relació al contingut de les dues introduccions, els d'ambdues obres responen a la definició clàssica de prefaci, que Genette sintetitza com:

\footnotetext{
un aparato típicamente retórico de persuasión (...) Lo que la retórica latina llamaba captatio benevolentiae (...). Diríamos, en términos más modernos, valorizar el texto sin indisponer al lector por una valoración demasiado inmodesta o demasiado visible de su autor. (...) En definitiva, valorizar el texto sin parecer valorizar a su autor (2001: 169).
}

Aquesta operació es materialitza de manera diferent en les dues obres. D'una banda, trobem Ramis que, en la seua introducció a La Alonsíada, assenyala que el motiu que l'ha portat a escriure la composició és donar a conéixer al públic els esdeveniments històrics narrats. També incideix en la veracitat de la composició i les notes històriques, d'acord amb «lo que nos dicen los autores de mejor fama y reputación» (Pons / Salord, 1985; Ramis, 1818: 3). Igualment, exposa la divisió del poema en tres cants i du a terme una excusatio propter infirmitatem, a través de la qual s'excusa per no haver sabut tractar el tema amb una major dignitat $i$ demana indulgència als lectors.

De l'altra banda, Albertí, en la seua introducció, comenta que els motius pels quals ha traduït el text original al català és pel seu «ardent i antig desitx de veure alguna producció en nostro desmesiat olvidat vulgar» (Pons / Salord 1985; Albertí 1818: 3), sumat a l'aparició de La Alonsíada de Ramis i la rellevància dels successos descrits. Després, el traductor objecta que no ha traduït les notes historiogràfiques perquè considera que els lectors interessats seran capaços de llegir-les en el castellà original. Per acabar, reprén la idea de l'excusatio propter infirmitatem amb la qual es posa al servei dels menorquins.

Arribats en aquest punt, és important assenyalar les diferències que rauen entre un $i$ altre paratext. En conseqüència, si bé els dos textos persegueixen la finalitat de lloar l'origen dels menorquins i d'Alfons III d'Aragó, sembla que cada autor s'adreça a un lector diferent. Per tant, Ramis ofereix un text en castellà acompanyat de tot un aparat de notes documentades que sembla destinat a un públic il lustrat i culte. En canvi, Albertí escriu en català i elimina les notes perquè s'adreça a un lector popular sense pretensions cultes.

\subsection{El resum de la vida d'Alfons III d'Aragó}

El Resumen de la vida d'Alonso III (Pons / Salord 1985; Albertí 1818: 7) és una instància prefacial que únicament es troba en la traducció albertiana de l'obra. Tal com indica el seu títol, es tracta d'una breu síntesi de les principals dades biogràfiques del monarca. Consegüentment, se citen els orígens familiars, el paper que va desenvolupar en la conquesta de l'illa de Menorca l'any 1287 i les circumstàncies en què va morir; de la mateixa manera, es glossen les seues virtuts, entre les quals es 
remarca la seua generositat, a causa del qual va ser sobrenomenat el Franc.

Aquest breu resum té la funció de presentar el protagonista de l'obra, Alfons III d'Aragó, al públic, tot just abans de començar el text poètic. La presència d'aquest paratext és significativa perquè les dades estan extretes de les notes historiogràfiques de Ramis; en concret, de les notes nou, tretze i catorze del cant I, i la quaranta-sis del cant III.

La reconversió de les notes de Ramis - que tenen una extensió que triplica la composició poèticaen un breu resum recolza la teoria que un i altre text estaven dirigits a lectors diferents. Albertí, conscient que el seu públic probablement no estaria interessat en les disquisicions històriques de Ramis, les va reformular per adequar-li-les, encara que fora d'una manera molt succinta que servira per presentar-los l'obra i situar-los en un context.

\subsection{Els incipits èpics}

En el seu estudi, Genette assenyala que bona part de les instàncies prefacials originalment estaven incloses dins de la pròpia obra, en les primeres o últimes línies del text (2001: 139). La pràctica, present en obres com la Ilíada o l'Odissea, solia col locar una invocació a les muses, l'anunci de la matèria i la determinació del punt de partida narratiu en els primers versos de les obres. Aquesta costum es va fixar en la tradició de l'epopeia, amb el sobrenom d'incipit èpic.

En aquest sentit, cal remarcar que tant l'Alonsíada de Ramis com la d'Albertí, inclouen aquest tipus d'instància prefacial, una sèrie de versos en què s'exposen fets extradiegètics de divers tipus. En concret, es tracta dels versos que conformen les cinc primeres estrofes de les dues composicions. En ells, Ramis i Albertí repeteixen les convencions del paratext i exposen que els poemes tractaran sobre la conquesta de Menorca per part d'Alfons III d'Aragó (vv. 1-8); que l'efemèride de tal fita històrica —el 17 de gener- hauria de ser recordada i celebrada pels menorquins (vv. 9-12); i, finalment, que han sigut sant Jordi i sant Antoni els qui han guiat els poetes, i no les muses, que són éssers fabulosos (vv. 13-20). La filiació d'aquestes cinc primeres estrofes al nivell extradiegètic converteix els versos vint-i-uné de les dues composicions («Había más de un siglo que a Menorca» i «El islamisme fals ja més d'un sigle havia») en el vertader inici dels texts de La Alonsíada i L'Alonsíada, respectivament.

Una vegada més, la presència d'els incipits èpics reforça la idea que els autors volien equiparar la història del poble menorquí a la de les grans nacions de l'antiguitat clàssica. Talment, revesteixen de grandiositat històrica els seus orígens, així com el monarca que va conquerir l'illa i la data en què va tenir lloc la gesta.

\subsection{Els postfacis}

La resta d'instàncies prefacials que trobem en les Alonsíades són postfacis, és a dir, paratexts que apareixen després del text poètic. Aquestes són exclusives de La Alonsíada de Ramis, ja que 
L'Alonsíada d'Albertí no compta amb cap paratext equivalent. Pel que fa al caràcter dels postfacis, Genette assenyala:

\begin{abstract}
Por su emplazamiento y su tipo de discurso, el posfacio no puede esperar ejercer más que una función curativa, o corretiva; se comprende que los autores prefieren las torpezas del prefacio a esa corrección final. Las virtudes del prefacio son, al menos, instructoras y preventivas [...] Pero, para el posfacio, es siempre a la vez muy pronto y muy tarde (2001: 203).
\end{abstract}

En l'obra de Ramis trobem els següents tres postfacis: el primer, una composició poètica breu i en castellà titulada Octavas, formada per setze versos, agrupats en dues estrofes de vuit versos cadascun. Segons les normes prosòdiques castellanes, els versos són hendecasíl labs i de rima assonant, encadenada en els sis primers versos i apariada els dos darrers de cada estrofa. Pel que fa al contingut, la primera estrofa funciona com una sinopsi de La Alonsíada, presentant el tema principal de l'obra; la segona repeteix l'exhortatio que trobem en la introducció de Ramis, en què s'estimula els menorquins a venerar la figura d'Alfons III d'Aragó.

El segon postfaci és una llista d'errates d'impressió amb les respectives correccions. Les errates mencionades pertanyen tant al text poètic com a les notes historiogràfiques, que comentarem després, i van assenyalades indicant-se la pàgina i la línia on apareixen, l'errata comesa i l'equivalent correcció. De les vint-i-tres correccions, la gran majoria (tretze d'elles) remeten a errors tipogràfics; quatre són addicions o correccions de mots que no apareixen en l'original; dos són correccions de temps verbals; altres dos són aclariments relatius a persones i anys que, per la manera com estan mencionats en el text original, poden donar lloc a confusions; finalment, hi ha una correcció que té a veure amb la puntuació i una altra relativa a la crida d'una nota historiogràfica, que va ser obviada inicialment.

El tercer i últim postfaci que trobem en La Alonsiada, és una llista de subscriptors de l'obra. En total, se citen seixanta-dos lectors subscrits que van adquirir setanta-vuit exemplars de la composició. És important assenyalar que el nom de Vicenç Albertí no apareix en la llista, cosa que indica que el menorquí no va adquirir el llibre sol licitant una còpia abans de la impressió. Al contrari, sembla que Ramis li va deixar l'exemplar original, tal com es pot llegir en la carta d'Albertí a Ramis: «Molt senyor meu i amic, torn a vostra mercè el manuscrit de La Alonsíada que s'ha servit traduir del castellà al nostro menorquí» (Pons / Salord 1985; Albertí 1818: 5).

De la mateixa manera, la llista de subscriptors és interessant perquè ens ajuda a conéixer millor el marc de referència dels autors. Seria il luminador posar en relació la llista de subscriptors de La Alonsíada amb aquelles que apareixen en altres obres del mateix període, context i autor, com, per exemple, Varones ilustres de Menorca (Ramis 1817: 271-272) o Antigüedades célticas de la isla de Menorca (Ramis 1818: 155-156), tot a fi de delimitar el nucli d'intel lectuals de la Menorca d'aleshores i la seua evolució. En qualsevol cas, un estudi d'aquests elements ultrapassaria les aspiracions d'aquest article i, per tant, no el durem a terme ací. 
Quant a l'obra d'Albertí, ja hem comentat que no compta amb cap d'aquests postfacis. Encara que l'autor mai arriba a evidenciar els motius pels quals els va elidir, ens sembla que hi ha raons suficients que expliquen la supressió de tots ells: en primer lloc, pel que fa a les Octavas, sembla que Albertí va optar per suprimir-les perquè el seu contingut és redundant, ja que apareix explicitat en altres paratexts, com la introducció del traductor, o en el propi text poètic.

En segon lloc, els motius que van motivar l'eliminació de la llista d'errates són purament pragmàtics, ja que la llista d'errates solament té sentit en relació amb el text original i queda desvirtuada en l'obra d'Albertí pel procés de traducció. Finalment, en tercer lloc, també trobem a faltar en l'obra d'Albertí una llista de subscriptors. Aquest paratext tampoc admet una traducció literal de l'original ramisià i els motius de la seua supressió són més obscurs.

Fins ara ja hem vist que els públics de les dues Alonsíades no són el mateix. En aquest sentit, creiem que l'aparició i supressió de la llista de lectors en una i altra obra respon a un criteri de prestigi. En el cas de Ramis, la seua llista apareix farcida de noms d'alts càrrecs civils, polítics i eclesiàstics, on els tractaments protocolaris i la menció del càrrec que cadascú ocupa és una constant. Per contra, imaginem que Albertí, que s'adreçava a un públic més popular i de proximitat, va suposar que tal paratext no tenia sentit en la seua obra. Al mateix temps, la direcció a un o altre grup de lectors justifica les decisions preses per Ramis i Albertí pel que fa a l'aparat paratextual, més ampli i procedimental en el primer; més lleuger i assequible en el segon.

\section{Els intertítols}

Sota el nom d'intertitols, s'agrupen aquells títols que delimiten una part del text, no el seu conjunt, i que es troben a l'interior de l'obra. Als intertítols, a més de les consideracions pròpies dels títols, hem d'afegir un parell més de connotacions. En primer lloc, que els intertítols només són accessibles als lectors del text. En segon lloc, que són de natura contingent, és a dir, que no són necessaris per a l'existència material o social de l'obra.

En els casos que tractem, les dues Alonsíades presenten una divisió interna idèntica, amb el text dividit en tres parts. En La Alonsíada de Ramis aquestes parts van identificades amb els intertítols Canto I, Canto II i Canto III. En L'Alonsíada d'Albertí no hi ha més variació que la traducció al català: Cant I, Cant II i Cant III.

Com veiem, es tracta d'intertítols remàtics, ja que no tenen res a veure amb el contingut dels poemes, però sí en la forma en què està organitzada l'obra. De fet, podríem dir fins i tot que estem davant d'intertítols doblement remàtics. D'una banda, la denominació de cant ens informa del gènere de la composició, ja que així s'anomenen les parts que conformen un poema èpic. De l'altra banda, la numeració en nombres romans serveix per ordenar-los. 
A més, tampoc no podem deixar de banda les implicacions de formalitat que es desprenen de la intertitulació remàtica. Aquesta decisió segueix una tradició iniciada en l'antiguitat clàssica que es va mantenir fins al segle XIX segons la qual:

La norma clásica de los intertítulos se divide en dos actitudes muy contrastadas y de connotaciones genéricas muy marcadas: la simple numeración de partes y capítulos corresponde a la ficción seria y la imposición de interítulos desarrollados, a la ficción cómica o popular» (Genette 2001: 260).

A banda dels intertítols que identifiquen cada cant, també hem de tenir en compte els que poden aparéixer en forma d'índex (una llista a banda que recull tots els intertítols) o cornises (recordatoris del títol i intertítol de l'obra en els màrgens superiors de les pàgines). En aquests sentit, cap de les dues Alonsíades presenta índexs. Pel que fa a les cornises, únicament en trobem en l'obra d'Albertí, que disposa en la cornisa de les pàgines senars el títol de L'Alonsíada i, en la cornisa de les pàgines parell, l'intertítol del cant corresponent.

Cap d'aquestes consideracions té un impacte essencial en la interpretació en clau política i civil dels textos. Si de cas, podríem dir que la divisió en cants — la divisió tradicional de l'epopeia— reforça una vegada més la hipòtesi de les obres escrites per enaltir els orígens del poble menorquí.

\section{Les notes}

El següent paratext que comentarem són les notes, un seguit d'esclariments de tipus historiogràfic que apareixen únicament en l'obra castellana. En total, hi ha cent quinze notes històriques: les seixanta-tres primeres corresponen al primer cant; les sis següents, al segon; i les quaranta-sis últimes, al tercer. Com ja hem vist abans, l'única resta supervivent d'aquestes notes en L'Alonsíada d'Albertí són unes poques ratlles fossilitzades en el Resum de la vida d'Alfons III d'Aragó.

Segons Genette, una nota és «un enunciado de extensión variable (una palabra es suficiente) relativo a un segmento más o menos determinado del texto, y dispuesto ya sea junto a ese segmento o en referencia a él» (Genette 2001: 272). L'origen de l'anotació es troba en l'Edat Mitjana, quan es va estendre el costum d'anotar esclariments en els màrgens de les pàgines. Aquest sistema va evolucionar a un més complex on s'introdueixen en el text diverses crides que remeten a les notes, que poden estar recollides a peu de pàgina, després del text o, fins i tot, constituir altre volum.

El narratòleg considera que la mateixa classificació que aplica per a les instàncies prefacials en termes d'autoria i règim (2001: 154), pot aplicar-se a les notes. D'acord amb la tipologia que proposa, en el cas que ens ocupa, parlaríem de notes amb un destinador autoral, autèntic i assertiu, ja que Ramis, persona real i autor, les reconeix com a pròpies. 
En canvi, el destinatari no és altre que el lector de La Alonsíada, a qui s'adrecen les notes per ser «conducentes a la mayor aclaración de este memorable suceso» (Pons / Salord 1985; Ramis 1818: 3). Tanmateix, no podem ignorar la possible existència de lectors que llegiren el text poètic, però no les notes, per no voler aprofundir més en la matèria. De la mateixa manera, a causa de la vàlua històrica de les notes de Ramis, tampoc no es pot descartar l'opció inversa: la d'un lector que, més interessat pel procés de recollida i contrastació de dades que per la vesant artística, llegira les notes però no el text poètic.

Malgrat això, amb les notes historiogràfiques de La Alonsíada entrem en l'àmbit més difós de tots els paratexts que presenten les dues obres. I és que moltes vegades les anotacions actuen en un camp intermedi entre el que seria pròpiament un paratext i una bifurcació momentània del text, equivalent a un parèntesi. Des d'un punt de vista estètic, sembla que les notes de Ramis no estan pensades amb una voluntat parentètica, com a notes que han de llegir-se a mesura que s'avança en la lectura del text poètic, ja que la seua prolixitat i llargària l'interromprien contínuament.

Aleshores, cal que ens preguntem quin paper juguen aquestes notes historiogràfiques. Arribats en aquest punt, ens agradaria apuntar en la direcció que les notes de Ramis realment no són un paratext de la composició poètica, sinó un text paral lel a aquest. De fet, hi ha elements que ens fan pensar que en La Alonsíada de Ramis conviuen dues obres diferents: d'una banda, un poema èpic; de l'altra, un text historiogràfic. Sembla que ho corroboren el fet que totes les notes històriques poden llegirse de manera continua, sense el text poètic, i tot i així conserven el sentit; talment, en les notes hi ha diversos lligams i referències que remeten, no al poema, sinó a altres notes. En aquest context de multiplicitat d'itineraris de lectura, les crides numerades serveixen per correlacionar ambdues obres i per demostrar que els esdeveniments narrats en el poema tenen una base científica.

La presència o absència de les notes històriques en cadascuna de les Alonsíades és una prova més que cadascun dels textos es dirigia a un públic diferent. La decisió de Ramis de conjuminar el text poètic $i$ un tractat d'historiografia es correlaciona directament amb la darrera etapa de la seua carrera literària, marcada per la producció d'informació enciclopèdica sobre l'illa de Menorca, adreçada a les autoritats i elits culturals peninsulars il lustrades (Martínez 2015: 41). Per contra, la decisió d'Albertí d'eliminar les notes històriques i substituir-les per una breus ratlles en el Resumen de la vida d'Alfonso III, té a veure amb la necessitat d'alleugerir l'obra de la càrrega científica i la seua vesant més il lustrada per tal de presentar-la a un públic menorquí i popular.

\section{L'epitext}

A banda del peritext -els paratexts que es troben materialment annexats al text- també hem de tenir en compte els epitexts, que són tots aquells elements paratextuals que circulen de manera independent al llibre. Exemples possibles d'epitexts els trobem en entrevistes, converses, col loquis, correspondències o diaris dels autors. 
Pel que fa als texts que ens ocupen, no trobem cap epitext de La Alonsíada de Ramis; en canvi, cal que mencionem el cas particular d'una carta que Ramis va escriure a Albertí i que, posteriorment, ell va incorporar a L'Alonsíada. Estem, doncs, davant d'un escrit concebut originàriament com a epitext, però reconvertit en peritext, per la manera com es presenta al lector juntament amb la resta de l'obra.

Els epitexts privats es caracteritzen per la presència d'un destinador (Ramis, en aquest cas) que s'adreça a un destinatari (Albertí). Amb la publicació del paratext, el destinatari es converteix en un mediador entre l'autor i el lector que rep el paratext. Igualment, la correspondència com a epitext privat té múltiples funcions que poden recórrer tot el procés de redacció d’un text, des de la seua gènesi fins a aclariments fets anys després de la publicació. El contingut de la carta que Ramis va escriure a Albertí es pot dividir en quatre punts: en primer lloc, un agraïment per l'honor que ha fet a La Alonsiada al traduir-la; en segon lloc, un elogi a les qualitats de la traducció; en tercer lloc, un fragment en què anima Albertí a escriure més obres en català; finalment, en quart lloc, l'acomiadament.

En l'epístola, Ramis menciona la seua La Alonsíada i el manuscrit traduït per Albertí que, segons sembla, li va mostrar abans de la publicació. Aquestes dates, junt amb la datació de la carta —que consta del tretze d'agost del 1818 —, ens poden ajudar a ubicar cronològicament la publicació dels dos textos.

Així, en els primers versos de l'incipit èpic de La Alonsíada, llegim: «Este es el dia, el dia memorable / en que Alonso III, rey invicto / plantó en Menorca, a fuerza de victorias / la santa fe, la fe de Jesucristo», (Pons / Salord 1985; Ramis 1818: 7). Aquesta data podria ser interpretada respecte a l'autor -indicant que Ramis va començar a escriure el poema el desset de gener del 1818-, o respecte al lector -i, per tant, el text ja estaria publicat aleshores. No obstant això, descartem aquesta segona interpretació perquè Ramis, al final de les notes històriques, firma el text a Mahó, amb data del 20 de febrer de l'any 1818. Altrament, cap la possibilitat que l'inicipit èpic no faça referència al moment de redacció de l'obra, i que la pretensió de Ramis fora que el text es llegira tal dia, coincidint amb l'aniversari dels actes que es commemoren. En canvi, la traducció d'Albertí, estaria redactada abans del tretze d'agost del mateix any, ja que Ramis afirma haver-la llegit aleshores. Per tant, cap esperar que la publicació de L'Alonsíada seria al voltant de la mencionada data, posterior a la rebuda del beneplàcit de Ramis.

És precisament aquest beneplàcit de l'autor del text original allò que explica la reconversió de la carta, concebuda com un epitext privat confidencial, en un peritext més de L'Alonsíada albertiana. I és que, amb la seua publicació juntament amb la resta del text, Albertí aconsegueix dos propòsits; d'una banda, demostrar que la seua traducció compta amb l'aprovació de Ramis; de l'altra, seduir els possibles lectors. Al cap i a la fi, quina millor recomanació per a una traducció que la de l'autor del text original, afirmant que gràcies a la tasca traductològica «podran passar a la posteritat així l'original com la traducció» (Pons / Salord 1985; Albertí 1818: 5). En qualsevol cas, seria interessant dur a terme una anàlisi més profunda de la carta de Ramis a Albertí en el marc de la tradició epistolar, ja que podria evidenciar, tal com afirma Salord (2009: 526), «el possible objectiu estratègic de la traducció/versió catalana de Vicenç Albertí». 
Altrament, és significativa la manera com Ramis esperona Albertí per tal que «de tems en tems nos ne donia altres [proves] de la seua habilitat en esta bella ciència» (Pons / Salord 1985; Albertí 1818: 6). Les línies apunten en la direcció que Ramis seguia interessat en la literatura en llengua catalana en la darrera etapa de la seua vida. Així, tot i que aleshores la seua producció era fonamentalment il lustrada i en castellà, afirma que les publicacions en català redundaven en «el lustro de nostro idioma y patria» (Albertí 1818: 6).

\section{Conclusions}

Com hem vist, del repàs dels paratexts que apareixen en La Alonsíada de Joan Ramis i L'Alonsíada de Vicenç Albertí es desprenen interesants conclusions relatives al caràcter polític i civil de les dues obres, els autors o el context. Així, sembla evident que les composicions es van escriure seguint els patrons de l'èpica clàssica, amb la finalitat de revestir de dignitat històrica els orígens del poble menorquí. Restes d'aquesta operació es troben fossilitzades en els títols, la divisió en cants, els incipits èpics i els epígrafs extrets de l'Eneida. De la mateixa manera, queden reforçades la imatge de l'heroi —Alfons III d'Aragó- i la data dels esdeveniments - dèsset de gener del 1818-, que arriba a proposar-se com a festa per als menorquins.

Per tal d'emparar aquesta idea, trobem paral lelament una tasca de reforçament de l'autor i de la certesa dels successos descrits. Aquest exercici es concreta en punts com la menció del càrrec de Ramis en la portada o la presència de les notes històriques que acompanyen el seu text. A més, hem vist com hi ha elements — referències creuades entre les notes, una possible lectura lineal de les mateixes— que ens fan pensar que en La Alonsíada de Ramis conviuen dues obres: un poema èpic i un tractat d'historiografia.

Finalment, també trobem en els paratexts diferències significatives que enllacen amb la idea que La Alonsíada i L'Alonsíada estaven adreçades a públics diferents. D’aquesta manera, se sumen a la diferència lingüística altres aspectes com la presència o absència de les notes històriques; l'aparició o no d'una llista de subscriptors; l'existència d'un aparat de postfacis de major o menor abundància i riquesa; o la informació contesa en la carta que l'autor va remetre al traductor. En conjunt, tots aquests factors no fan sinó evidenciar la coexistència a Menorca de dos grups de lectors: una elit cultural i il lustrada que llegia en castellà, i un sector popular i de proximitat que ho feia en català. 
Carlos Martínez Mayor. Els llindars de les Alonsíades. Els paratexts en La Alonsíada, de Joan Ramis, i L'Alonsíada, de Vicenç Albertí

\section{Bibliografia}

Ayensa, E. (2008) «El tema almogàver en la literatura grega i catalana dels segles XIX i XX. Bases per a una nova èpica», dins Malè, J. i Miralles, E. (coords.) Formes modernes de l'èpica, del segle XVI al segle XX, Santa Coloma de Queralt, Obrador Edèndum, pp. 114-127.

Carbonell, J. (1964a) «El període menorquí de la literatura catalana», dins El llibre de tothom. Barcelona, Editorial Alcides, pp. 159-163.

(1964b) «La cultura a Menorca», Serra d’Or, any VI, 11, pp. 13-24.

(1967) «L’obra literària de Joan Ramis i Ramis», Revista de Menorca, 55, pp. 5-64.

(ed.) (1968) Joan Ramis, Lucrècia, Barcelona, Edicions 62.

Cayuela, A. (1996) Le paratetxte au Siècle d'Or; prose romanesque, livres et lecteurs en Espagne au XVIIe siècle, Ginebra, Librairie Droz.

Dolç, M. (trad.) (1975) Publi Virgili Maró, Eneida, text revisat i traducció, I-II, Barcelona, Fundació Bernat Metge / Tipografia Emporium, 2 vol.

Gella, J. (ed.) (1989) Joan Ramis, Resumen topográfico e bistórico de Menorca, Madrid, Real Academia de la Historia.

Genette, G. (1989), Palimpsestos. La literatura en segundo grado, Madrid, Taurus.

(1997) Paratexts: Tresholds of interpretation, Cambridge, Cambridge University Press.

(2001) Umbrales, Coyoacán/Buenos Aires, Siglo Veintiuno Editores / Siglo XXI Editores.

Hernández, F. (1987) Cultura i societat a Menorca, Menorca, Institut Menorquí d’Estudis, 2 vol. [inclou l'edició de Poemes polítics de circumstàncies].

Marfany, M. (2016) «La traducció catalana de Vicenç Albertí de La Alonsíada de Joan Ramis (1818): el trasllat de la versificació», Randa, 76, pp. 51-57.

Martínez, C. (2015) L'Alonsiada de Vicenç Albertí $i$ Vidal, edició crítica i estudi, València, Universitat de València, [treball final de màster inèdit].

Mas, J. (dir) / Perelló, F. (coord.) (2003-2006) Diccionari de teatre a les Illes Balears, Barcelona, Publicacions de l'Abadia de Montserrat, 2 vol.

Melchor, V. de (ed) (1982) Joan Ramis, Arminda, drama en tres actes, Bellaterra, [edició de l'autor]. (2001) «Un clàssic menor de la literatura catalana: Lucrècia o Roma lliure (1769) de Joan Ramis i Ramis», dins Rossich, A. (coord.) El teatre català dels orígens al segle XVIII, Kassel, Reichenberger, pp. 399-406.

Miralles, E. (2007a) «Vicenç Albertí, traductor de Metastasio», dins Malé, J. i Miralles, E. Mites clàssics en la literatura catalana i contemporània, Barcelona, Universitat de Barcelona, pp. 39-58. 
Carlos Martínez Mayor. Els llindars de les Alonsíades. Els paratexts en La Alonsíada, de Joan Ramis, i L'Alonsíada, de Vicenç Albertí

(2007b) «Joan Ramis i Ramis. Arminda, a cura de Vicent de Melchor i Pep Valsalobre», Arxin de textos catalans antics (ATCA), Barcelona, Institut d'Estudis Catalans / Facultat de Teologia de Catalunya, 26, pp. 881-884.

(2012) «Las traducciones catalanas en el siglo XVIII y el primer tercio del XIX», Revista Dieciocho: Hispanic enlightenment, vol.35, 1, pp. 125-136.

Paredes, M. (1999a) «Les reminiscències dels clàssics llatins en l'obra literària de Joan Ramis», dins Paredes, M / Salord, J. (ed.) Joan Ramis i Josep M. Quadrado: de la Il lustració al Romanticisme, Barcelona, Universitat de les Illes Balears / Institut Menorquí d'Estudis / Publicacions de l'Abadia de Montserrat, pp. 146-147.

(1999b) «Traductors i traduccions a la Menorca il lustrada», dins Lafarga, F. (ed.) La traducción en España (1750-1830). Lengua, literatura, cultura, Lleida, Universitat de Lleida, pp. 79-89.

Pons, A. J. (1984) «Vicenç Albertí i Vidal, traductor menorquí del segle XIX», Els Marges, 31, pp.107-114.

(1987) «Caetera ex scriptis pete: notes sobre l'obra de Joan Ramis», Randa, 21, p. 109-129.

(ed.) (1988) Joan Ramis, Poesies burlesques i amoroses, Menorca, Institut Menorquí d’Estudis.

Pons, A. J. / Salord, J. (eds.) (1985) Vicenç Albertí / Joan Ramis, La Alonsíada, Maó, Consell Insular de Menorca.

Ramis, J. (1817) Varones ilustres de Menorca y noticia de los apellidos que más se han distinguido en ella, Maó, Impremta de Pedro Antonio Serra.

(1818) Antigüedades célticas de la isla de Menorca desde los tiempos más remotos hasta el siglo IV de la Era cristiana, Maó, Imprenta de Pedro Antonio Serra.

Salord, J. (1990) «Poesies burlesques i amoroses de Joan Ramis: la mirada abraçadora d'un il lustrat», Serra d'Or, 367, pp. 62-64.

(2009) «Joan Ramis», dins Rossich, A. Panorama critic de la literatura catalana, III, Barcelona, Vicens Vives, pp. 516-533.

(2012) «La Menorca ilustrada: creación y proyección», Revista Dieciocho: Hispanic enlightenment, vol. 35,1 , pp. 168-178.

Salord, M. (1992) «Els entremesos traduïts per Albertí: recreació literària i incorporació de la realitat menorquina», dins Carbonell, J. (coord.) Estudis de llengua i literatura catalanes XXIV, miscel lània 3, Barcelona, Abadia de Montserrat, pp. 201-214.

(1997) «Vicenç Albertí i Vidal: la traducció com a exercici de (re)creació literària», dins Vicenç Albertí, Entremesos I, Menorca, Institut Menorquí d’Estudis, pp. 7-31. 